\title{
Money, Inflation, and Economic Growth: Some Updated Reduced Form Results and Their Implications
}

\author{
KEITH M. CARLSON
}

$\mathrm{T}$

HE economic experience of the United States during the 1950s and 1960s provided an opportunity to develop and test a number of hypotheses relating to the performance of the macroeconomy. One such hypothesis that received empirical support during this period held that monetary actions, as measured by movements in the monetary aggregates, have lasting effects on only nominal variables. This proposition is an important element in a body of thought called "monetarism."1

In contrast to the relative economic tranquility of the $1950 \mathrm{~s}$ and $1960 \mathrm{~s}$, the decade of the $1970 \mathrm{~s}$ was marked by extensive experimentation with wage and price controls, large supply shocks, proliferation of government regulations, and worldwide inflation. These events and developments prompted economists to question whether or not the performance of the United States economy during this period was consistent with prior hypotheses relating to the lasting impact of monetary actions. This article is addressed to that question.

The article focuses on the magnitude of the response of GNP, output, and the price level to changes in the money stock, defined as currency plus private

1For an extensive discussion of monetarism, see Thomas Mayer, et. al, The Structure of Monetarism (New York: W. W. Norton and Company, 1978). checkable deposits. ${ }^{2}$ The magnitudes of these responses are derived by estimating reduced form equations; that is, equations in which observations of the rates of change of economic variables are regressed on current and lagged values of the rate of change of money and other suitably chosen exogenous variables. The sum of the coefficients on the money variable is interpreted as a measure of the magnitude of response during the sample period from which the observations are drawn. ${ }^{3}$

\section{THE QUANTITY EQUATION OF EXCHANGE AND REDUCED FORMS}

The underlying framework for the analysis is the quantity equation of exchange. This equation is an identity that states the value of all spending for goods and services in two ways: the product of the stock of money times its velocity of circulation, and the

The regressions were run before data were available for the new definitions of the monetary aggregates. Data for "old" MI were used, and ATS and NY NOW accouts were added after III $/ 78$.

3Whether or not this magnitude of response can be interpreted statistically as a "long-nun" result depends on the length of the lag relative to the number of observations in the sample period. A reliable estimate of the long-rum response of a variable that adjusts quickly and completely to an exogenous shock does not require as many observations as does a slowly adjusting variable. 
price level times the quantity of aggregate output. In symbols, this identity is:

(1) $\mathrm{MV} \equiv \mathrm{PX} \equiv \mathrm{Y}$,

where

$$
\begin{aligned}
& \mathrm{M}=\text { nominal money stock, } \\
& \mathrm{V}=\text { velocity of circulation, } \\
& \mathbf{P}=\text { price level, } \\
& \mathrm{X}=\text { output, and } \\
& \mathrm{Y}=\text { nominal GNP. }
\end{aligned}
$$

As an identity, the quantity equation of exchange means little. When combined with assumptions relating to the determination of the variables, however, the equation assumes behavioral content. Writing the equation in rate of change form, where each of the variables is allowed to be influenced by money, yields the following:

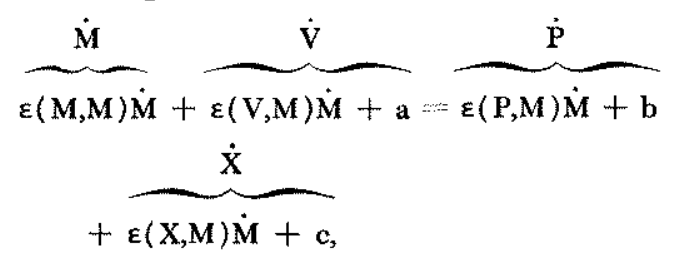

where $\varepsilon$ is the elasticity of the first variable in parentheses with respect to the second. A dot over a variable indicates its compounded annual rate of change. The constants, $a, b$, and $c$, represent the effect of nonmonetary influences on $\dot{V}, \dot{P}$, and $\dot{X}$, respectively.

The total differential of equation 2 results in an expression that relates the elasticities to each other:

(3) $\mathbf{1}+\varepsilon(\mathbf{V}, \mathbf{M})=\varepsilon(\mathbf{P}, \mathbf{M})+\varepsilon(\mathbf{X}, \mathbf{M})$,

or

(4) $1+\varepsilon(V, M)=\varepsilon(Y, M)$.

Equations 3 and 4 indicate the constraints that must be considered when attempting to estimate these elasticity parameters. An estimate of either $\varepsilon(\mathrm{V}, \mathrm{M})$ or $\varepsilon(Y, M)$ implies the other. Given one of these elasticities, only one of the remaining elasticities $\varepsilon(P, M)$ or $\varepsilon(\mathbf{X}, \mathbf{M})$ - can be estimated. Alternatively, estimates of $\varepsilon(P, M)$ and $\varepsilon(X, M)$ imply both $\varepsilon(\mathrm{V}, \mathrm{M})$ and $\varepsilon(\mathrm{Y}, \mathrm{M})$.

The elasticity parameters and the constants in equation 2 can be estimated in a variety of ways. Reduced form equations could be estimated for $\dot{Y}$ and $\dot{P}, \dot{Y}$ and $\dot{X}, \dot{P}$ and $\dot{X}, \dot{V}$ and $\dot{P}$, or $\dot{V}$ and $\dot{X}$. The choice is arbitrary only if the error terms for each of these reduced form equations have exactly the same serial correlation properties. ${ }^{4}$ Monetarists researching the

"See Yash P. Mehra "An Empirical Note on Some Monetarist Propositions," Southern Economic Journal (July 1978), pp. 154-67.
U.S. economy have generally concentrated on $\dot{Y}$ and $\dot{\mathrm{P}}$, although not always in combination. ${ }^{5}$ Nelson recently developed justification for this choice of variables by testing the hypothesis that the structure of the United States economy is recursive, with disturbances from GNP flowing to the price level and not the reverse. ${ }^{6}$ Consequently, this article focuses on reduced form estimates of $\dot{\mathrm{Y}}$ and $\dot{\mathrm{P}} .^{\mathrm{T}}$

\section{REDUCD FORM RESULTS}

The empirical analysis of the impact of monetary actions on GNP, output, and the price level uses previous specifications by monetarists as a starting point and modifies these specifications in light of the experience of the $1970 \mathrm{~s} .{ }^{8}$ After the equations are summarized and the variables are defined, the equations are first estimated using data from 1955 through 1969. They are then estimated with data from the 1970 s. Of primary interest is the stability of the relationships when data from the 1970 s are incorporated into the estimates.

\section{Specifications and Definitions of Variables}

The GNP equation is specified as follows:

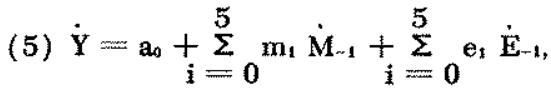

where

$\dot{\mathrm{Y}}=$ compounded annual rate of change of nominal GNP,

$\dot{M}=$ compounded annual rate of change of $\mathrm{M} 1$ (plus ATS deposits and NY NOW accounts after III/78), and

$\dot{\mathrm{E}}=$ compounded annual rate of change of high employment federal expenditures.

This equation is essentially the same as that estimated

\footnotetext{
5 For example, see Leonall C. Andersen and Keith M. Carlson, "A Monetarist Model for Economic Stabilization," this Review (April 1970), pp. 7-25, and William G. Dewald and Maurice N. Marchon,"A Modified Federal Reserve Bank of St. Louis Spending Equation for Canada, France, Germany, Italy, the United Kingdom and the United States," Kredit and Kapital $(1978)+$ pp. $194-212$.

eCharles R. Nelson, "Recursive Structure in U.S, Income, Prices, and Output," Journal of Political Economy (December 1979), pp. 1307-27.

7 Additional justification for the $\dot{Y}-\dot{P}$ combination is found in Thomas A. Gittings, "A Linear Model of the Long-Run Neutrality of Money," Staff Memoranda, Federal Reserve Bank of Chicago (1979).

"The specifications summarized here are the "preferred" results of estimating a variety of specifications.
} 


\section{Table 1}

\section{Estimates of Reduced Form Equations with Pre-1970 Data (Sample Period: $1 / 55-1 V / 69)^{1}$}

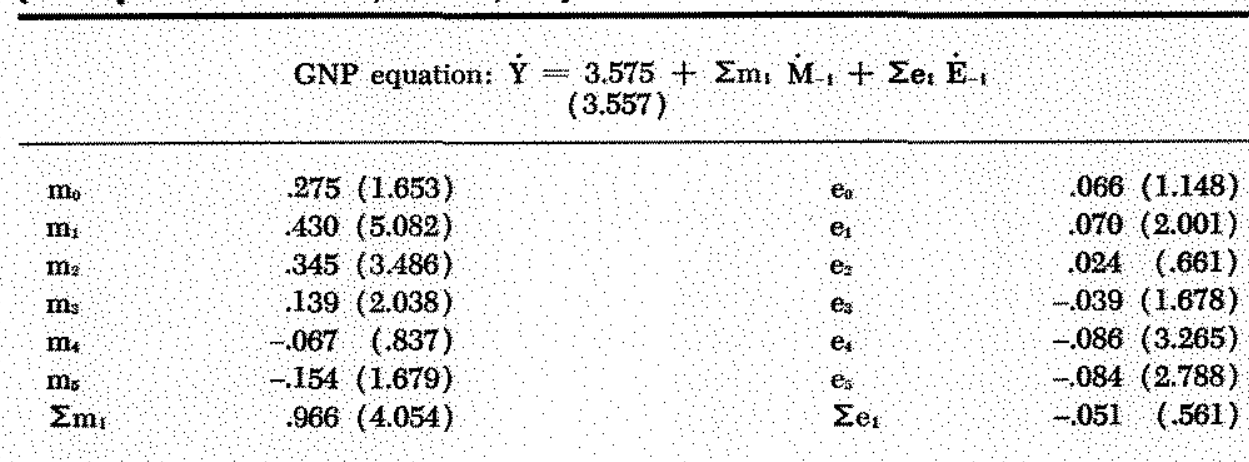

$\mathrm{R}^{2}=438 \mathrm{~S}, \mathrm{E}_{\mathrm{L}}=3.361$ and D.W $=1.934$

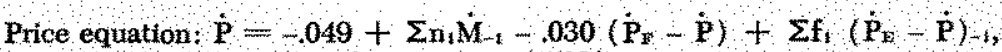
$(133)$ $(509)$

\begin{tabular}{|c|c|c|c|c|c|}
\hline $\boldsymbol{I}_{\mathrm{a}}$ & $042(1,077)$ & $\mathbf{n}_{11}$ & $.062(4,321)$ & $f_{i}$ & $-.002(062)$ \\
\hline$n_{1}$ & $036(1.365)$ & $\mathbf{n}_{12}$ & $.065(4.433)$ & $\mathbf{f}_{\mathrm{i}}$ & $004(230)$ \\
\hline $\mathbf{n}_{\mathrm{F}}$ & $.033(1811)$ & $\mathbf{n}_{\mathrm{s}}$ & $.068(4.293)$ & $\mathrm{f}_{\mathrm{z}}$ & $007(358)$ \\
\hline$n_{\mathrm{s}}$ & $0032(2,220)$ & $n_{14}$ & $.068(4.014)$ & $f_{i}$ & $.007(381)$ \\
\hline $\mathbf{n}_{4}$ & $.033(2.318)$ & $\mathbf{n}_{13}$ & $.067(3.703)$ & $f_{i}$ & $.005(262)$ \\
\hline $\mathbf{n}_{\mathbf{s}}$ & $035(2.309)$ & $\mathbf{n}_{16}$ & $.063(3.414)$ & $\mathbf{f}_{5}$ & $003(149)$ \\
\hline$n_{0}$ & $.039(2.400)$ & $n_{n z}$ & $.057(3.164)$ & $\Sigma \mathbf{f}_{4}$ & $.024(.279)$ \\
\hline$\dot{n}_{i}$ & $043(2.631)$ & $\mathrm{n}_{*{ }^{*}}$ & $.048(2.953)$ & & \\
\hline $\mathbf{n}_{\boldsymbol{s}}$ & $.048(2.995)$ & $\mathbf{n}_{19}$ & $.036(2.777)$ & & \\
\hline $\mathbf{n}_{*}$ & $.053(3.463)$ & $\mathrm{n}_{\mathbb{S}}$ & $.020(2.629)$ & & \\
\hline $\mathbf{n}_{10}$ & $.058(3.954)$ & $\Sigma n_{1}$ & $1.008(7.420)$ & & \\
\hline
\end{tabular}

$\mathrm{R}^{2}=.559 ;$ S.E. $=1.094 ;$ and D.W. $=1.996$.

All polynomial distributed lags are third degree with tail constraint only; figures in parentheses are absolute values of t-statistics; a dot over a variable indicates compounded annual rate of change.

by Andersen and Jordan in $1968,{ }^{9}$ but modified so that the coefficients are constrained on a third degree polynomial distributed lag with $t-6=0$.

The price equation is specified as follows:

(6) $\dot{\mathrm{P}}=\mathrm{b}_{0}+\mathrm{b}_{1} \mathrm{D}_{1}+\mathrm{b}_{2} \mathrm{D}_{2}+\mathrm{b}_{2}\left(\dot{\mathrm{P}}_{\mathrm{y}}-\dot{\mathrm{P}}\right)+\underset{\mathrm{i}=0}{\stackrel{20}{\sum} \mathrm{n}_{1} \dot{\mathrm{M}}_{-1}}$

$$
+\underset{\mathbf{i}=0}{\sum_{0}} \mathrm{f}_{1}\left(\dot{\mathrm{P}}_{\mathrm{E}}-\dot{\mathrm{P}}\right)_{-1}
$$

where

$\dot{\mathrm{P}}=$ compounded annual rate of change of the GNP deflator,

9Leonall C. Andersen and Jerry L. Jordan, "Monetary and Fiscal Actions: A Test of Their Relative Importance in Economic Stabilization," this Review (November 1968), pp. $11-24$.
$\mathrm{D}_{1}=$ wage and price control dummy,

$\mathbf{D}_{2}=$ decontrol dummy,

$\dot{\mathrm{P}}_{\mathrm{F}}=$ compounded annual rate of change of the food deflator,

$\dot{\mathrm{M}}=$ compounded annual rate of change of $\mathrm{M} 1$ (plus ATS deposits and NY NOW accounts after $\mathrm{III} / 78$ ), and

$\dot{\mathrm{P}}_{\mathrm{E}}=$ compounded annual rate of change of producer prices for fuels, related products, and power.

This specification builds on one developed by Karnosky except that it introduces variables designed to capture the influence of nonmonetary shocks on the 
price level. ${ }^{10}$ The polynomial distributed lag is third degree for both money and energy prices with constraints of $\mathrm{t}-21=0$ and $\mathrm{t}-6=0$, respectively.

\section{Results Using Pre-1970 Data}

Table 1 summarizes the estimated equations using data prior to the onset of the shocks of the 1970 s. For the 1955-69 period, GNP was dominated by movements in the money stock, and the adjustment to these changes was essentially complete after five quarters. The elasticity of GNP with respect to the money stock, as measured by the sum of the coeffcients on money, was not significantly different from one at the 5 percent level and implied that the elasticity of velocity with respect to money was zero.

LoDenis S. Kamosky, "The Link Between Money and Prices 1971-76," this Review (June 1976), pp. 17-23.
With the sum of the coefficients on high employment expenditures not significantly different from zero, the constant term was an estimate of the trend growth of velocity. Based on these estimates, the equilibrium growth rate of GNP during the $1955-69$ period was equal to the growth rate of money plus the trend rate of change of velocity.

According to the estimated price equation, the rate of change of the price level was also dominated by the growth rate of the money stock in the 1955-69 period. Other factors, namely food and energy prices, were not significant in explaining overall price movements during this period, thus confirming Karnosky's estimate for essentially the same period. The pattern of the estimated coefficients indicated that prices adjust to a monetary shock very slowly, but the total effect after 20 quarters was an elasticity of the price level equal to one. Since neither the constant term

Table 2

Estimates of the GNP Equation'

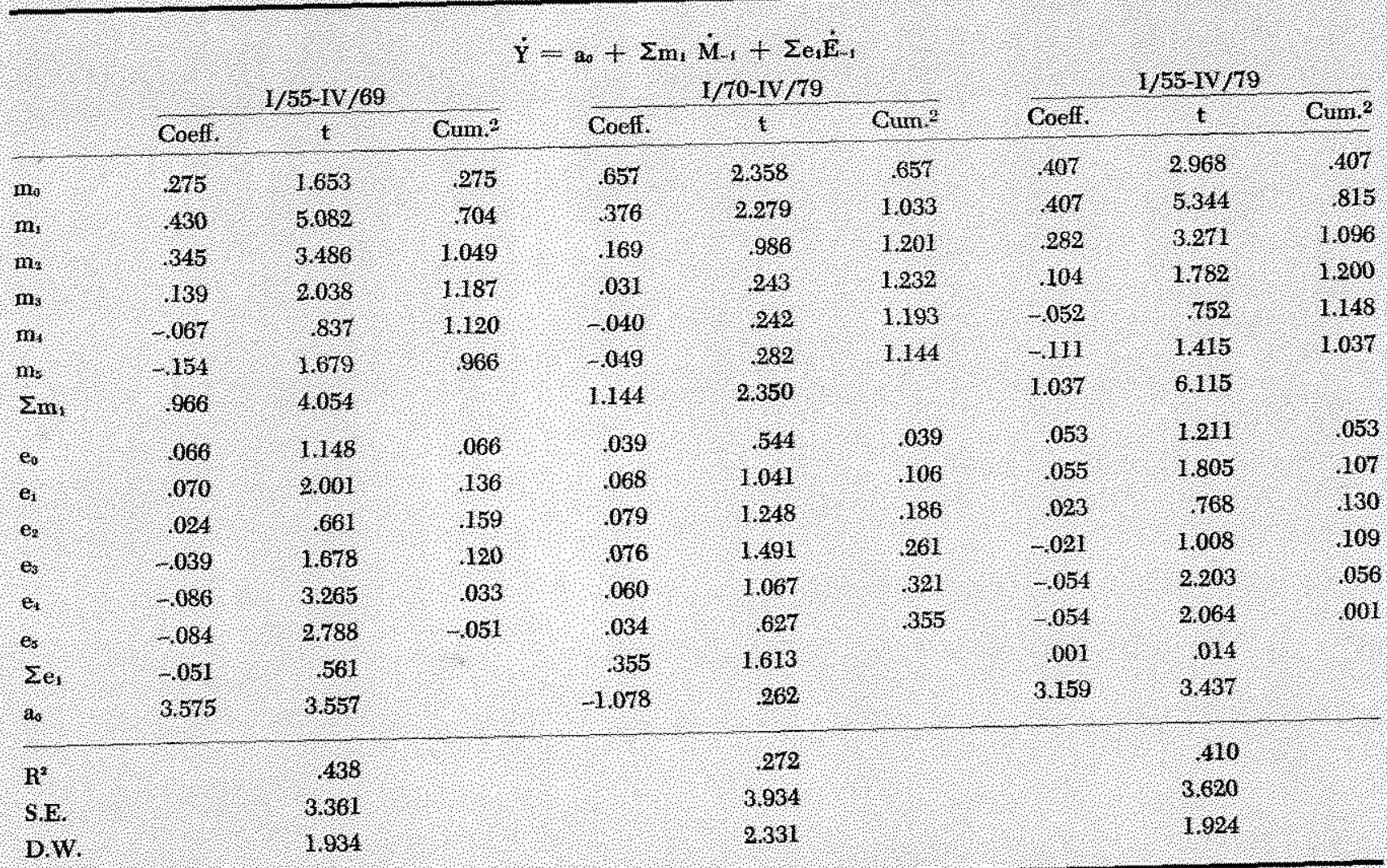

AAl polynomial distributed lags are third degree with tail constrant only, t-statisties are absolute values, a dot over a vari able nilleates compounded amnal rate of ehange.

2Nimbers are the enmulative sum of coefficients. 
Table 3

Estimates of the Price Equation

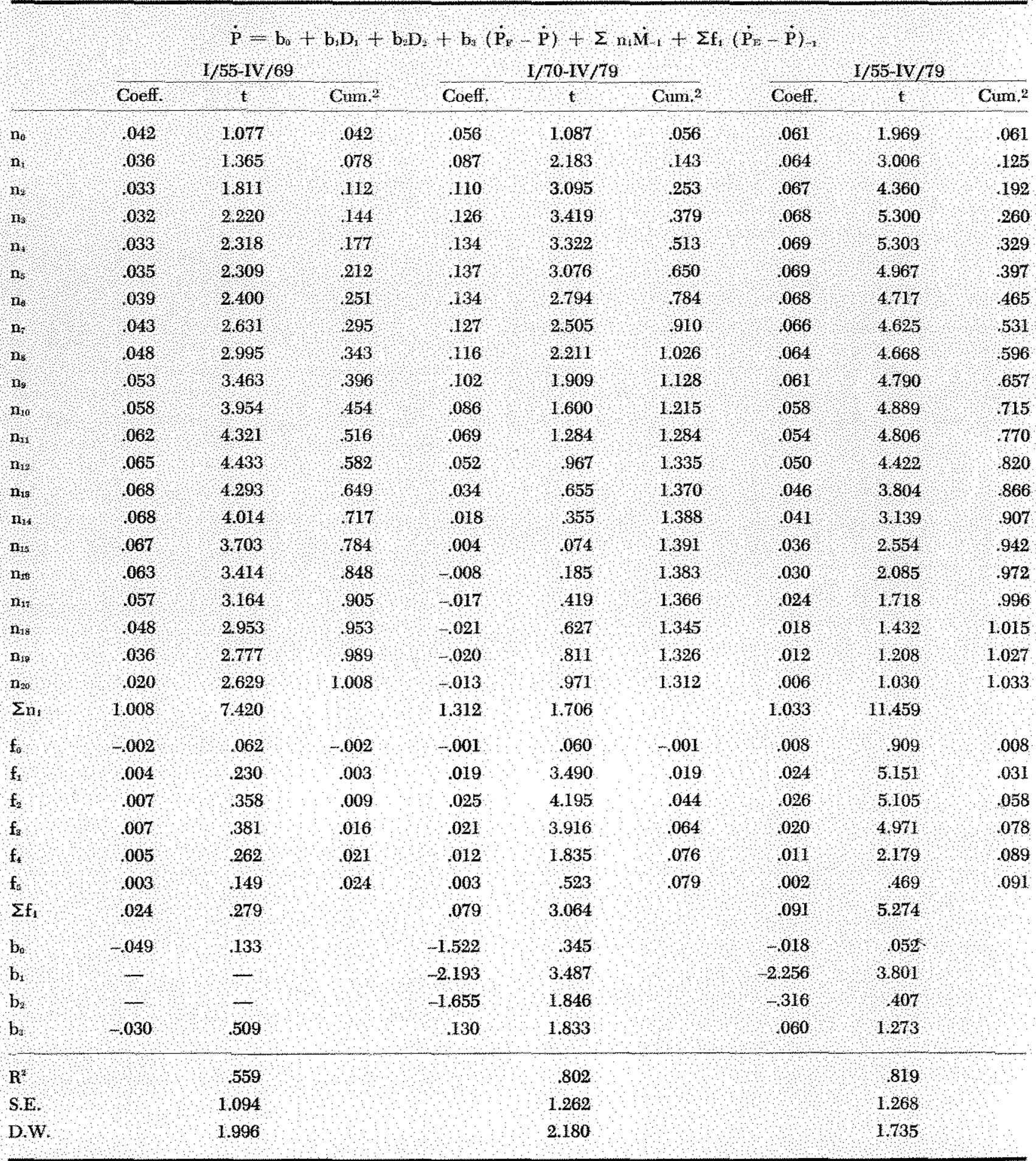

1 All polynonial distributed lags are third degree with tail constrant only $t$-statistics are absolute values, a dot over a vari able ndicates conpounded amnal ate of change, $D_{i}$ and $D_{\text {s }}$ are wage and price control and decontrol dummes, respectively.

Numbers are the cumulative sum of coefficients. 


\section{Table 4}

Results of Chow Test (1/55-IV/69 vs. 1/70-IV/79)

\begin{tabular}{|c|c|c|c|}
\hline & Gitical $\mathrm{F}$ & Calculated F & Conclusion \\
\hline CNP equation & $\mathrm{F}_{\infty}(\mathrm{s, \infty})=2,12$ & 1,20 & Cammot refeet $\mathrm{H}$, \\
\hline Price equalion & $F_{6},(8,89)=2,05$ & 3.23 & Reject H$_{1}$ \\
\hline
\end{tabular}

Mi, is the aull hypothesis that the reglession equations are equal for the two sample periods.

nor the effect of nonmonetary shocks were significantly different from zero, the equilibrium rate of change of the price level during this sample period was equal to the rate of monetary growth.

These two estimated equations implied that the equilibrium rate of output growth was independent of the rate of monetary expansion during the 1955-69 period. This implication was derived from an examination of the elasticity estimates in conjunction with equations 3 and $4 ; \varepsilon(Y, M)=1$ and $\varepsilon(P, M)=1$ together implied that $\varepsilon(X, M)=0$. In other words, these estimated reduced form equations substantiated the hypothesis that monetary actions have lasting effects on only nominal variables.

\section{Updated Results}

Tables 2 and 3 present the results using data from the 1970s. For purposes of comparison, the pre-1970 estimates are also summarized. The Chow test was used to check the equations for stability.

Estimated Equations - Updated estimates for the GNP equation are shown in table 2 and for the price equation in table 3. Results are shown both for the $1970 \mathrm{~s}(\mathrm{I} / 70-\mathrm{IV} / 79)$ and for the extended sample pe$\operatorname{riod}(\mathrm{I} / 55-\mathrm{IV} / 79)$

The sum of the coefficients on money in the GNP equation was not significantly different from one at the 5 percent level, either for the $1970 \mathrm{~m} 79$ period or for the fully extended sample period 1955-79. Estimates of the constant, however, indicated a decline in the trend growth of velocity when data for the 1970s were included. For the 1970-79 sample period, the estimated constant was negative but not significantly different from zero at the 5 percent level. For the fully extended sample period, however, the constant was positive and significantly different from zero, but the point estimate was less than that for the $1955-69$ period.

The estimate of the price equation for the 1970-79 period showed an increase in the sum of the coeffi- cients on money. However, this sum was not significantly different from zero at the 5 percent level. For the fully extended sample period, the sum of the money coefficients was significantly different from zero, although not significantly different from one at the 5 percent level.

Estimates of the remaining coefficients indicate that nonmonetary factors, namely energy prices and wage and price controls, influenced price level movements during the 1970s, and to such an extent that they were also significant over the full sample period. Estimates of the constant term for both the 1970-79 and 1955-79 periods were not significantly different from zero at the 5 percent level.

Tests for stability - The updated results suggest some conflicting conclusions. The Chow-test of stability was used to investigate further the appropriateness of simply extending the sample period to include the 1970s. ${ }^{11}$ Table 4 summarizes the results of applying this test to the GNP and price equations.

The test results show that the hypothesis of stability for the GNP equation for the two sample periods was not rejected. However, the hypothesis of stability was rejected for the price equation. The interpretation of these results is that the GNP equation, as estimated over the full sample period, can be used to summarize that relationship. However, the choice of the estimated price equation depends on the period that is chosen for analysis. ${ }^{12}$

\section{Implications of the Results for the Relationship between Money and Output}

One implication of the reduced form results using data prior to 1970 was that the equilibrium rate of

\footnotetext{
${ }^{11 G r e g o r y ~ C h o w, ~ " T e s t s ~ o f ~ E q u a l i t y ~ B e t w e e n ~ S e t s ~ o f ~ C o e f f i-~}$ cients in Two Linear Regressions;" Econometrica (July 1960 ), pp. $591-605$.

12These price equations should not be interpreted as long run equations, however, because the sample periods are so short. See footnote 3.
} 
output growth was independent of monetary growth. In other words, trend output was determined by real factors: namely, growth of the labor force, capital stock, and technology.

When the reduced form equations were updated with data from the 1970s, the implication for equilibrium output was modified. In a strict statistical sense, the hypothesis that monetary actions have lasting effects only on nominal variables was not rejected when data from the 1970s were included in estimating the relationships. However, when the estimated GNP equation for the full sample period was combined with the price equation for the 1970-79 period, the growth of money appeared to influence the rate of growth of output. Although $\varepsilon(Y, M)$ was still approximately one, the point estimate of $\varepsilon(\mathrm{P}, \mathrm{M})$ was 1.31 . Consequently, based on the experience of the 1970 s, the point estimate of $\varepsilon(\mathrm{X}, \mathrm{M})$ was - .31 .

The nature of this result, although statistically tentative, is summarized in table 5 . Underlying the calculations in this table is the assumption that nonmonetary shocks equal zero. These results, although they do not demonstrate causality, provide indirect support for the view that there is a negative relation between the trend rate of monetary growth (and inflation) and the trend rate of economic growth.

This contention that inflation adversely affects output has received increasing emphasis in the recent literature..$^{13}$ One view is that inflation slows growth by discouraging investment and saving via the exist. ing tax structure. ${ }^{14}$ The inflation process increases effective tax rates for both individuals and firms and lowers after-tax rates of return, thereby reducing incentives to invest and save.

Another argument stresses the uncertainty associated with inflation, ${ }^{15}$ If higher and higher inflation rates also mean greater risks associated with investment planning, saving and investment will be discouraged because a given expected rate of return will be accompanied by a greater variance.

${ }^{13}$ For general discussions of possible factors contributing to the slowdown of productivity in the 1970s, see Edward $\mathrm{F}$; Denison, "Explanations of Declining Productivity Growth," Survey of Current Business (August 1979), pp. 1-24; and John A. Tatom, "The Productivity Problem," this Review (September 1979), pp. 3-16.

${ }^{14} \mathrm{~A}$ recent study providiug evidence relating to the effect of inflation on corporate rates of return is reported in Martin Feldstein and Lawrence Summers, "Inflation and the Taxation of Capital Income in the Corporate Sector," National Tax Journal (December 1979), pp. 445-70.

${ }^{15}$ See Stephen L. Able, "Inflation Uncertainty, Investment Spending, and Fiscal Policy," Federal Reserve Bank of Kansas City Economic Review (February 1980), pp. 3-13.

\section{Table 5}

\section{Relationship between Trend Output and Money Growth}

\begin{tabular}{|c|c|c|}
\hline \multirow{2}{*}{$\begin{array}{l}\text { Rate of growth } \\
\text { of noney }\end{array}$} & \multicolumn{2}{|c|}{ Rate of growth of output based on. } \\
\hline & Pre, 1970 results & Updated results \\
\hline $0 \%$ & $3,62 \%$ & $468 \%$ \\
\hline 2 & 3.54 & 4,13 \\
\hline 4 & 3.46 & 3,58 \\
\hline 6 & 337 & 3.03 \\
\hline 8 & 3.29 & 248 \\
\hline
\end{tabular}

1 These calculations are based on the point estimates of the parameters in the GNP and pice equations and assume that nonmonetary influences are equal to zero except for the constant terms:

Still another explanation of the inflation-growth connection is that the inflation process introduces "noise" into the price signals that are transmitted from consumers to producers. ${ }^{16}$ As a result, the general efficiency of the price system in allocating resources is reduced. Such a reduction must be manifested in a reduced growth rate of output.

\section{SUMMARY}

This article presents updated reduced form results relative to the hypothesis that monetary actions have a lasting impact on only nominal variables. When data from the 1970 s were included in the sample, this hypothesis could not be rejected for either the 1970-79 period or the 1955-79 full sample period.

When the reduced form equations were tested for stability over the entire period, the hypothesis of stability for the GNP equation could not be rejected; but the null hypothesis for the price equation was rejected. When the GNP equation for the fully extended sample period was combined with the price equation for the 1970-79 period, the point estimates of the coefficients suggested that the rate of growth of output was negatively related to the growth rate of money during the 1970s. Even though only suggestive, the results provide tentative evidence to support the notion that real economic gain can be achieved by reducing the trend growth of money. ${ }^{17}$

\footnotetext{
16Milton Friedman, "Nobel Lecture: Inflation and Unemployment," Journal of Political Economy (June 1977), pp. 451-72.

17Laurence H. Mever and Robert H. Rasche, "On the Costs and Benefits of Anti-Inflation Policies," this Review (February 1980 ), pp. 3-14.
} 